\title{
STUDI KOMPARASI MODEL PEMBELAJARAN THINK PAIR SHARE (TPS) DAN DRILL AND PRACTICE DILENGKAPI MEDIA KEY-RELATION CHART TERHADAP PRESTASI BELAJAR SISWA PADA MATERI TERMOKIMIA
}

\author{
Firstma Khoerunnisa, Suryadi Budi Utomo*, dan Endang Susilowati \\ Program Studi Pendidikan Kimia, FKIP, Universitas Sebelas Maret, Surakarta, Indonesia \\ * Keperluan korespondensi, email: sbukim98@yahoo.com
}

\begin{abstract}
ABSTRAK
Penelitian ini bertujuan untuk mengetahui apakah model pembelajaran Think Pair Share (TPS) lebih baik dibandingkan model pembelajaran Drill and Practice yang keduanya sama-sama dilengkapi Key-Relation Chart pada materi Termokimia. Penelitian ini menggunakan metode eksperimen dengan desain Randomized Pretest-Posttest Comparison Group Design. Populasi dalam penelitian ini adalah seluruh siswa kelas XI MIA semester ganjil SMA Negeri Ajibarang tahun pelajaran 2015/2016. Pengambilan sampel dilakukan secara cluster random sampling. Pengumpulan data dilakukan menggunakan teknik tes dan non tes. Teknik tes untuk mengukur prestasi belajar siswa aspek pengetahuan. Sedangkan teknik non tes untuk mengukur prestasi belajar aspek sikap dan keterampilan siswa. Analisis data menggunakan uji t-pihak kanan . Berdasarkan hasil perhitungan statistik menggunakan software SPSS 16 diperoleh signifikasi 0,0675 . Hasil tersebut menunjukkan bahwa model pembelajaran Drill and Practice sedikit lebih baik dibandingkan model pembelajaran Think Pair Share (TPS). Kedua model sama-sama dilengkapi media Key-Relation Chart. Prestasi belajar aspek sikap dan aspek keterampilan tidak terpengaruh oleh kedua model pembelajaran tersebut.
\end{abstract}

Kata Kunci: Think Pair Share (TPS), Drill and Practice, Key-Relation Chart,uji t-pihak kanan

\section{PENDAHULUAN}

Pendidikan bermaksud membatu peserta didik untuk menumbuh kembangkan potensi-potensi kemanusiaannya [1]. Seiring dengan berkembangnya potensi tingginya kesadaran seseorang untuk memperoleh pendidikan yang bagus. Hal tersebut mengindikasikan majunya satu bangsa. Usaha pemerintah untuk mengimbangi besarnya minat seseorang terhadap pendidikan adalah dengan memperbaiki kualitas pendidikan yang sudah ada. Hal itu ditempuh dengan cara merubah dan memperbaiki kurikulum tahun demi tahun. Kurikulum yang saat ini digunakan adalah kurikulum 2013. Pembelajaran pada kurikulum 2013 menggunakan pendekatan saintifik atau pendekatan berbasis proses keilmuan. Pendekatan saintifik meliputi lima pengalaman belajar yaitu mengamati, menanya, mengumpulkan informasi, mengasosiasi dan mengkomunikasikan.

Prestasi belajar siswa merupakan tolak ukur keberhasilan suatu proses pembelajaran. Prestasi belajar dapat diukur pendidik melalui proses penilaian. Berdasarkan acuan penilaian hasil belajar pada kurikulum 2013, aspek yang dinilai oleh pendidik mencakup kompetensi sikap (spiritual dan sosial), pengetahuan dan keterampilan. Salah satu faktor yang mempengaruhi prestasi belajar siswa adalah model pembelajaran. Model pembelajaran merupakan teknik yang digunakan pendidik untuk menangani suatu kegiatan pembelajaran. Dengan menggunakan model yang tepat maka materi pelajaran dapat tersampaikan dengan baik kepada siswa.

Berdasarkan pengamatan keadaan di SMA Negeri Ajibarang tahun ajaran 
2015/2016, nilai pada mata pelajaran kimia khususnya materi termokimia memiliki nilai rata-rata 70 dan tergolong masih dibawah kriteria ketuntasan minimal yaitu 75 . Materi termokimia merupakan cabang ilmu kimia yang mempelajari tentang kalor reaksi. Konsep-konsep menghitung perubahan entalpi reaksi perlu diperdalam agar siswa mampu memilih cara untuk menyelesaikan soal termokimia. Maka, perlu diupayakan suatu bentuk pembelajaran yang mampu membantu siswa mengatasi kesulitan belajar.

Nilai yang rendah merupakan salah satu ciri adanya kesulitan belajar. Masalah kesulitan belajar dapat diatasi salah satunya dengan menerapkan model pembelajaran. Berkaitan dengan hal tersebut maka pendidik harus menerapkan model pembelajaran yang cocok untuk materi termokimia agar isi dari materi tersebut tersampaikan dengan baik kepada siswa, sehingga berimbas pada prestasi belajar siswa yang semakin baik. Model pembelajaran yang dipilih adalah Think Pair Share (TPS) dan Drill and Practice.

Model pembelajaran Think Pair Share (TPS) terdiri dari kegiatan berpikir, berpasangan dan mengkomunikasikan. Model pembelajaran Think Pair Share (TPS) menggunakan media Key Relation-Chart lebih baik dari pada menggunakan media LKS pada materi termokimia [2]. Kelebihan dari model ini adalah siswa dapat mengungkapkan jawaban kepada pasangannya. Model pembelajaran ini sudah terbukti cocok pada materi termokimia dengan dilengkapi media Key Relation-Chart (KR-Chart).

Model pembelajaran Drill and Practice merupakan teknik pengajaran yang dilakukan berulang kali untuk mendapatkan keterampilan, dibutuhkan untuk mengingat secara matematis. Model pembelajaran Drill and Practice tepat diterapkan dalam pembelajaran materi hitungan, bahasa asing dan peningkatan perbendaharaan kata-kata (vocabulary) [3]. Model pembelajaran Drill and Practice menggunakan media Crossword Puzzle lebih efektif dibandingkan menggunakan model pembelajaran Learning Cycle $5 E$ menggunakan media Crossword Puzzle [4].

Untuk mendukung keberhasilan pencapaian hasil pembelajaran menggunakan model pembelajaran Think Pair Share (TPS) dan model pembelajaran Drill and Practice perlu didukung dengan adanya media pembelajaran yang relevan. Media pembelajaran merupakan sumber-sumber belajar selain guru yang berguna sebagai penyalur atau penghubung pesan ajar yang diadakan dan/atau diciptakan secara terencana oleh para guru atau pendidik [5]. Media yang digunakan dalam penelitian ini adalah Key-Relation Chart (KR Chart). $K R$ Chart merupakan lembaran yang berisi hubungan tentang fakta, konsep dan prinsip yang penting dari suatu materi yang dipelajari. $K R$ Chart dibuat sedemikian rupa untuk menarik perhatian siswa agar mempermudah pemahaman siswa terhadap materi termokimia.

\section{METODE PENELITIAN}

Penelitian ini dilaksanakan di SMA Negeri Ajibarang tahun ajaran 2015/2016 pada kelas XI MIA. Penelitian ini menggunakan metode eksperimen dengan desain Randomized PretestPosttest Comparison Group Design. Rancangan ini menggunakan 2 kelompok subjek. Adapun bagan desain Randomized Pretest-Posttest Comparison Group Design terdapat dalam Tabel 1.

\section{Tabel 1. Bagan desain Randomized Pretest-Posttest Comparison Group Design}

\begin{tabular}{cccc}
\hline $\begin{array}{c}\text { Kelas } \\
\text { Eksperimen }\end{array}$ & Pretest & Perlakuan & Posttest \\
\hline I & $\mathrm{T}_{1}$ & $\mathrm{X}_{1}$ & $\mathrm{~T}_{2}$ \\
II & $\mathrm{T}_{1}$ & $\mathrm{X}_{2}$ & $\mathrm{~T}_{3}$ \\
\hline
\end{tabular}

Keterangan :

$\mathrm{T}_{1}=$ prestasi siswa pada pokok bahasan termokimia sebelum diberi perlakuan

$\mathrm{T}_{2}=$ prestasi siswa pada pokok bahasan termokimia setelah diberi perlakuan model pembelajaran Think Pair Share

$\mathrm{T}_{3}=$ prestasi siswa pada pokok bahasan termokimia setelah diberi perlakuan model pembelajaran Drill and Practice

$\mathrm{X}_{1}=$ perlakuan dengan model pembelajaran Think Pair Share 
$\mathrm{X}_{2}=$ perlakuan dengan model pembelajaran Drill and Practice

Variabel bebas dalam penelitian ini adalah model pembelajaran Think Pair Share (TPS) menggunakan media KeyRelation Chart dan model pembelajaran Drill and Practice menggunakan media Key-Relation Chart. Populasi dalam penelitian ini adalah seluruh siswa kelas XI MIA semester ganjil SMA Negeri Ajibarang tahun pelajaran 2015/2016 yang terdiri dari 6 kelas. Sampel yang digunakan dalam penelitian yakni kelas XI MIA 4 sebagai kelas eksperimen I yang diberi perlakuan pembelajaran menggunakan model pembelajaran Think Pair Share dan kelas XI MIA 5 sebagai kelas eksperimen II yang diberi perlakuan model pembelajaran menggunakan metode Drill and Practice.

Teknik pengambilan sampel yang digunakan adalah cluster random sampling atau sampel acak. Sedangkan teknik pengumpulan data utama yang digunakan dalam penelitian ini dilakukan dengan dua teknik yaitu tes dan non tes. Tws digunakan untuk mengukur prestasi siwa ranah pengetahuan. Sedangkan teknik non tes yang terdiridari angket dan observasi dilakukan untuk mengukur prestasi siswa ranah sikap dan ketrampilan.

Instrumen penelitian adalah alat atau fasilitas yang digunakan oleh peneliti dalam mengumpulkan data [6]. Instrumen tes pengetahuan diuji validitas keseluruhan butir soal dengan formula Gregory. Serta reliabilitas dapat dicari dengan menggunakan rumus $\mathrm{KR}_{20}$. Untuk taraf kesukaran dan daya beda dianalisis menggunakan ITEMAN. Instrumen penilaian sikap hanya dilakukan uji validitas dan reliabilitas. Sedangkan penilaian ketrampilan hanya dilakukan uji validitas isi.

Analisis data yang digunakan meliputi uji prasyarat analisis yang terdiri dari uji normalitas, uji homogenitas variansi populasi,dan uji t-matching. Semua uji tersebut dilakukan dengan bantuan software IBM SPSS 16. Sedangkan uji hipotesis dilakukan menggunakan uji t-pihak kanan.

\section{HASIL DAN PEMBAHASAN}

Data yang didapatkan pada penelitian ini adalah nilai prestasi belajar pada materi pokok Termokimia yang meliputi aspek pengetahuan, aspek sikap dan aspek keterampilan. Data diperoleh dari kelas XI MIA 4 sebagai kelas eksperimen I dengan model pembelajaran Think Pair Share (TPS) dilengkapi dengan media Key RelationChart dan kelas XI MIA 5 sebagai kelas eksperimen II yang dikenai model pembelajaran Drill and Practice dilengkapi dengan media Key RelationChart. Sebelum dilakukan pembelajaran materi pokok Termokimia terlebih dahulu dilakukan pretest untuk aspek pengetahuan. Setelah dilakukan pretest, masing-masing kelas dikenai model pembelajaran yang sudah ditentukan. Model pembelajaran dilakukan sebanyak tiga kali tatap muka untuk setiap kelas. Selanjutnya pada akhir pembelajaran materi pokok Termokimia dilakukan posttest untuk mengetahui seberapa besar prestasi belajar siswa. Bersamaan dengan proses pembelajaran, penilaian sikap dan keterampilan siswa juga diambil.

Data penelitian mengenai prestasi belajar meliputi aspek pengetahuan, sikap dan keterampilan siswa pada materi pokok termokimia kelas eksperimen I dan kelas eksperimen II dapat dilihat pada Tabel 2.

Tabel 2. Rangkuman Deskripsi data Penelitian.

\begin{tabular}{lcc}
\hline \multirow{2}{*}{$\begin{array}{c}\text { Jenis } \\
\text { Penilaian }\end{array}$} & \multicolumn{2}{c}{ Nilai } \\
\cline { 2 - 3 } & $\begin{array}{c}\text { Eksperimen } \\
\text { I }\end{array}$ & $\begin{array}{c}\text { Eksperimen } \\
\text { II }\end{array}$ \\
\hline $\begin{array}{l}\text { Pretes } \\
\text { Pengetahuan }\end{array}$ & 40,87 & 41,12 \\
$\begin{array}{l}\text { Postes } \\
\text { Pengetahuan }\end{array}$ & 84,50 & 81,87 \\
$\begin{array}{l}\text { Selisih Nilai } \\
\text { Pengetahuan }\end{array}$ & 43,62 & 40,75 \\
Nilai Sikap & 03,00 & 03,00 \\
Nilai & 02,95 & 02,96 \\
Ketrampilan & & \\
\hline
\end{tabular}

Berdasarkan nilai pretes pengetahuan dapat diketahui bahwa kelas uang akan digunakan memiliki kemampuan yang sama. Setelah 
dilakukan post-test, diketahui selisih nilai pada kelas eksperimen I sebesar 43,62 sedangkan pada kelas eksperimen II sebesar 40,75. Hal ini menunjukan bahwa model pembelajaran Think Pair Share (TPS) dan Drill and Practice memberikan hasil prestasi yang lebih baik. Uji prasyarat analisis digunakan sebelum melakukan uji hipotesis. Salah satu syarat yang harus terpenuhi adalah sampel berasal dari populasi yang berdistribusi normal. Uji yang digunakan adalah Uji Shapiro-Wilk dengan menggunakan software SPSS 16. Hasil uji normalitas dapat dilihat pada Tabel 3.

Tabel 3. Hasil Uji Normalitas Nilai Pretest Pengetahuan, selisih Nilai Pengetahuan, Sikap dan Keterampilan

\begin{tabular}{llc}
\hline Parameter & \multicolumn{1}{c}{ Kelas } & Signifikansi \\
\hline \multirow{2}{*}{ Pretes } & Eksperimen I & 0,056 \\
& Eksperimen II & 0,124 \\
\multirow{2}{*}{ Selisih Nilai } & Eksperimen I & 0,422 \\
& Eksperimen II & 0,113 \\
Sikap & Eksperimen I & 0,000 \\
& Eksperimen II & 0,000 \\
\multirow{4}{*}{ Ketrampilan } & Eksperimen I & 0,000 \\
& Eksperimen II & 0,000 \\
\hline
\end{tabular}

Berdasarkan tabel tersebut maka data pretest pengetahuan dan data selisih nilai pengetahuan masuk statistik parametrik. Selanjutnya dilakukan Uji Homogenitas menggunakan Levene's test. Hasil Uji Homogenitas dapat dilihat pada Tabel 4.

Tabel 4. Hasil Uji Homogenitas

\begin{tabular}{lrr}
\hline \multicolumn{1}{c}{ Parameter } & Signifikansi & Kesimpulan \\
\hline Pretes & 0,725 & Homogen \\
Selisih Nilai & 0,316 & Homogen \\
Pengetahuan & 0,000 & Homogen \\
Sikap & 1,000 & Homogen \\
\hline
\end{tabular}

Langkah berikutnya adalah melakukan uji keseimbangan pada nilai pretest menggunakan uji One way ANOVA.
Hasil uji keseimbangan dengan parameter pretes menunjukan nilai signifikasi sebesar 0,915 yang berarti tidak ada perbedaan. Hasil uji prasyarat analisis menunjukkan bahwa sampel seimbang yang artinya kedua kelas memiliki prestasi awal yang sama. Model pembelajaran Think Pair Share merupakan model pembelajaran kooperatif yang dirancang untuk mempengaruhi pola interaksi siswa. TPS memiliki sintak (1) berpikir, (2) berpasangan, dan (3) berbagi. Model pembelajaran TPS terbukti mampu meningkatkan prestasi belajar siswa aspek pengetahuan karena nilai rata-rata post-test di atas batas ketuntasan minimal. Sedangkan model pembelajaran Drill and Practice menekankan pada pemberian latihan terus menerus dengan harapan siswa memiliki kemampuan menyelesaikan soal termokimia yang diberikan oleh guru. Berdasarkan nilai post-test, model pembelajaran Drill and Practice juga mampu meningkatkan prestasi belajar aspek pengetahuan.

Media yang digunakan dalam penelitian ini adalah Key-Relation Chart. Media Key-Relation Chart diberikan setelah kedua kelas eksperimen melakukan pretest. Chart adalah salah satu alat yang penting bagi pengajaran dan pendidikan [7]. Key-Relation Chart merupakan lembaran yang berisi hubungan tentang fakta, konsep dan prinsip yang penting dari suatu materi yang dipelajari.

Untuk mengetahui pengaruh perlakuan yang diberikan pada kelas eksperimen I (Think Pair Share dilengkapi Key-Relation Chart) dan kelas eksperimen II (Drill and Practice dilengkapi Key-Relation Chart) dilakukan uji perbandingan pada selisih nilai pengetahuan, nilai sikap dan nilai keterampilan. Uji hipotesis yang digunakan untuk mengetahui ada tidaknya perbedaan selisih nilai pengetahuan adalah uji t-dua sampel independen satu sisi untuk sisi atas (uji t-pihak kanan).

Hasil uji hipotesis selisih nilai pengetahuan dengan t-test menunjukan nilai signifikasi sebesar 0,0675 yang berarti $\mathrm{H}_{0}$. diterima. Berdasarkan data hasil perhitungan uji t menggunakan software SPSS 16 diperoleh signifikansi 
0,0675 . Hasil tersebut lebih besar dari 0,05 sehingga $H_{0}: \mu_{1} \leq \mu_{2}$ diterima. Sehingga dapat disimpulkan bahwa rerata selisih nilai pengetahuan kelas eksperimen I (Think Pair Share yang dilengkapi media Key-Relation Chart) lebih rendah atau sama dengan kelas eksperimen II (Drill and Practice yang dilengkapi media Key-Relation Chart).

Uji hipotesis yang digunakan untuk mengetahui ada tidaknya perbedaan nilai sikap adalah Uji Kruskal-Wallis. Hasil uji Kruskal-Wallis pada nilai keterampilan menunjukan nilai signifikasi sebesar 0,280 yang berarti $\mathrm{H}_{0}$ diterima. Sama halnya dengan uji hipotesis nilai sikap, uji hipotesis nilai keterampilan juga menggunakan Uji Kruskal-Wallis. Hasil uji Kruskal-Wallis pada nilai keterampilan menunjukkan nilai signifikan sebesar 0,280 yang berarti $\mathrm{H}_{0}$ diterima. Kedua hasil tersebut menunjukkan perlakuan yang dikenai pada sampel tidak memberikan pengaruh.

\section{KESIMPULAN}

Berdasarkan hasil analisis serta mengacu pada perumusan masalah yang telah diuraikan pada bab sebelumnya, dapat disimpulkan bahwa penggunaan model pembelajaran Think Pair Share (TPS) dengan media KeyRelation Chart memberikan hasil prestasi belajar aspek pengetahuan kurang dari sama dengan model pembelajaran Drill and Practice dengan media Key-Relation Chart pada materi Termokimia. Hasil ini diperoleh dengan perhitungan statistik menggunakan software SPSS 16 diperoleh signifikansi 0,0675 . Hasil tersebut lebih besar dari 0,05 sehingga $\mathrm{H}_{0}: \mu_{1} \leq \mu_{2}$ diterima. Sedangkan pada prestasi belajar aspek sikap dan aspek keterampilan tidak terpengaruh oleh kedua model pembelajaran tersebut.

\section{UCAPAN TERIMA KASIH}

Bapak Drs. Tjaraka Tjunduk, M.Pd., selaku Kepala SMA N Ajibarang yang telah memberikan kesempatan dan tempat guna pengambilan data dalam penelitian. Serta Bapak Pudjiarto, S.Pd., selaku Guru mata pelajaran Kimia kelas $\mathrm{XI}$ SMA $\mathrm{N}$ Ajibarang yang telah memberikan bimbingan dan bantuan dalam penelitian.

\section{DAFTAR RUJUKAN}

[1] Tirtarahardja, U. \& Sulo, S.L.L. (2005). Pengantar Pendidikan. Jakarta : Rineka Cipta.

[2] Aini, N., Ashadi, \& Nurhayati, N.N.(2014). Studi Komparasi Pembelajaran Think Pair Share (TPS) Dilengkapi Dengan Media Key Relation-Chart(KR-Chart) dan LKS Terhadap Prestasi Belajar Siswa Pada Materi Termokimia Kelas XI Semester Ganjil SMA N 1 Sukoharjo Tahun Ajaran 2013/2014. Jurnal Pendidikan Kimia (JPK),3 (3) : 98104.

[3] McDonough, Sharon K. (2005). Way Beyond Drill and Practice : Foreign Language Lab activities in support of Constructivist Learning. Int'l $J$ of Instructional Media. Vol: 28(1)

[4] Nurhayati, F., Redjeki, T., \& Utami, B.(2013). Efektivitas Pembelajaran Dengan Metode Drill and Practice dan Learning Cycle 5E Disertai Media Pembelajaran Crossword Puzzle Terhadap Prestasi Belajar Siswa Pada Materi Pokok Hidrokarbon Kelas X Semester Genap SMA Negeri Kebakkramat Tahun Pelajaran 2012/2013.Jurnal Pendidikan Kimia (JPK), 2(3) : 191198.

[5] Munadi, Y.(2008). Media Pembelajaran. Jakarta : Gaung Persada Press.

[6] Arikunto, S.(2012). Dasar-Dasar Evaluasi Pendidikan. Jakarta : Bumi Aksara.

[7] Hamalik, O. (1989). Media Pendidikan. Bandung : Rineka Cipta 